\title{
4
}

\section{A participação da agricultura familiar no Programa Nacional de Alimentação Escolar: estudo de casos em municípios paulistas da região administrativa de Campinas}

\author{
Paulo Eduardo Moruzzi Marques ${ }^{1}$, Morgane Retière ${ }^{2}$, Nayla Almeida ${ }^{3}$ e Carolina Ferraz \\ dos Santos ${ }^{4}$
}

A participação da agricultura familiar no Programa Nacional de Alimentação Escolar (PNAE) constitui a questão chave deste artigo. Nesta perspectiva, nosso estudo se dirigiu à discussão relativa ao funcionamento dos conselhos municipais de alimentação escolar (CAE) de Americana, Cosmópolis e Piracicaba. Trata-se de uma análise sobre as aquisições de produtos da agricultura familiar, interrogando em que medida o Programa Nacional de Alimentação Escolar é considerado como um meio para promover o desenvolvimento local com ênfase no fortalecimento dos agricultores familiares. O conceito de referencial de circuitos curtos de proximidade, vinculado à sustentabilidade agroalimentar, foi considerado em nossa análise. Foram entrevistados, em 2015 e 2016, atores chave do programa nos municípios escolhidos. Nossa pesquisa permitiu constatar que todas as prefeituras estudadas realizam compras de produtos provenientes da agricultura familiar. Porém, o fomento ao desenvolvimento local está longe de alcançar o que é recomendado nos documentos do PNAE. Para atingir o mínimo de 30\% dos recursos do Fundo Nacional de Desenvolvimento da Educação (FNDE) transferidos aos municípios para a aquisição de gêneros alimentícios advindos da agricultura familiar, as prefeituras consideradas recorrem frequentemente a organizações distantes de agricultores familiares.

Palavras-chave: alimentação escolar, agricultura familiar, desenvolvimento local sustentável, segurança alimentar, políticas públicas, circuitos curtos de proximidade.

\footnotetext{
${ }^{1}$ Professor do Programa de Pós-Graduação Interunidades (CENA-ESALQ) em Ecologia Aplicada da Universidade de São Paulo - PCH/LES/ESALQ/USP. Endereço para correspondência: Av. Pádua Dias no 11, CEP: 13418-900, Piracicaba - SP. Tel.: (19) 3447-8592, ramal 205. E-mail: pmarques@usp.br

${ }^{2}$ Doutoranda do Programa de Pós-Graduação em Ecologia Aplicada Interunidades (ESALQ-CENA) da Universidade de São Paulo e da Université Paris VIII. E-mail: morgane.retiere@gmail.com

${ }^{3}$ Graduanda em Engenharia Agronômica da ESALQ/USP. E-mail: alyan.almeida@gmail.com

${ }^{4}$ Graduanda em Engenharia Agronômica da ESALQ/USP. E-mail: carouferraz@gmail.com
} 
O lugar da agricultura familiar na alimentação escolar. Moruzzi Marques et al.

\section{The participation of family farming at the Nacional School Feeding Program: case studies in municipalities at the administrative area of Campinas}

The participation of family farming at the Nacional School Feeding Program (PNAE) is the focus of this discussion. In this perspective, our study discusses about the functioning of the municipal councils of school feeding (CAE) from Americana, Cosmópolis and Piracicaba. This is an analysis about the purchases of the family farming questioning in what way the Nacional School Feeding Program is considered a way to promote the local development with an emphasis on Family farming. The referential concept of short circuits of proximity as a manner to promote the agri-food sustainability was considered in our analysis. Were interviewed key players at the chosen cities, in 2015 and 2016. Our research allowed to notice that all the studied mayors realize the purchases of family farming products, however, the incentive to the local development is far beyond the recommended at the PNAE documents. To achieve the minimum of $30 \%$ of the destination from the Nacional Fund of Development of the Education in the acquisition of foodstuffs came from family farming, the mayors turn to far away organizations of family farmers.

Keywords: school feeding, family farming, local development, public policy, short circuits, food security.

\section{INTRODUÇÃO}

Este artigo é resultado de projetos de pesquisa desenvolvidos sobre o funcionamento do Programa Nacional de Alimentação Escolar em três municípios (Piracicaba, Americana e Cosmópolis) $)^{5}$. A motivação inicial destas investigações se associa às atividades do Núcleo de Agroecologia Nheengatu da ESALQ/USP (formado por sete coletivos de estudo e extensão atuando em diferentes áreas), cuja atuação no assentamento Milton Santos possibilitou constatar as grandes dificuldades que as familias assentadas encontram para escoar seus produtos via canais institucionais de compra de alimentos da agricultura familiar. No referido núcleo, o grupo Cajan (Comercialização Justa e Cultura Alimentar) atua com vistas a fomentar discussões e a formular respostas acerca da comercialização de produtos agroecológicos oriundos da agricultura familiar. A partir desta perspectiva, a ideia de examinar com profundidade os problemas sobre o fornecimento de produtos dos agricultores familiares para a alimentação escolar ganhou corpo.

Deste modo, foram concebidos os projetos de pesquisa "Programa Nacional da Alimentação Escolar: o lugar da agricultura familiar" e "Discursos sobre o Programa Nacional de Alimentação Escolar: a participação de produtos oriundos do assentamento Milton Santos em questão", que foram incorporados a uma investigação de maior porte financiada pela FAPESP intitulada "Críticas e justificações em torno de alternativas agrícolas no estado de São Paulo: a reconstrução das relações urbano e rural em questão".

Este artigo reúne resultados destas pesquisas para focalizar a questão relativa ao funcionamento dos conselhos municipais de alimentação escolar (CAE) de Americana, Cosmópolis e Piracicaba em relação à participação da agricultura familiar no Programa Nacional de

${ }^{5}$ Colaboraram no desenvolvimento destas pesquisas Mariah Silva Leandro Campos, Enzo Carlini Spelta, Nathanael José de Campos e Daniele Cristina dos Santos Silva. 
O lugar da agricultura familiar na alimentação escolar. Moruzzi Marques et al.

Alimentação Escolar a partir das posições de diferentes atores. Nesta ótica, trata-se também de discutir características das compras de produtos da agricultura familiar no âmbito das referidas administrações municipais. Nesta linha, o problema da investigação apresentada neste artigo pode ser formulado da seguinte maneira: em que medida o Programa Nacional de Alimentação Escolar é considerado como um meio para promover o desenvolvimento local com ênfase na agricultura familiar? A hipótese orientadora desta pesquisa foi que o papel da agricultura familiar para o desenvolvimento local e para um abastecimento de alimentos saudáveis é pouco reconhecido no âmbito da gestão local do PNAE, podendo dificultar a superação de obstáculos para uma maior participação dos agricultores familiares no programa.

Para o desenvolvimento desta reflexão, são apresentadas a seguir a evolução recente do Programa Nacional de Alimentação Escolar e as escolhas teóricas e metodológicas desta investigação. $\mathrm{Na}$ parte final do artigo, são examinados os discursos de atores chave considerados na pesquisa e o funcionamento da alimentação escolar nos municípios focalizados.

\section{O PROGRAMA NACIONAL DE ALIMENTAÇÃO ESCOLAR EM QUESTÃO}

A alimentação escolar representa um braço importante das ações públicas concebidas com vistas à segurança alimentar. Desde notadamente 2003, tais ações são planejadas de forma a articular intensamente o fornecimento de alimentos para populações específicas, em particular aquela escolar, e o apoio à agricultura familiar. Esta orientação com vistas a favorecer a compra de alimentos oriundos dos agricultores familiares para o abastecimento de instituições de assistência social, escolas, creches, hospitais, quartéis e restaurantes populares foi concebida no âmbito do Conselho Nacional de Segurança
Alimentar e Nutricional (CONSEA) e do Programa Fome Zero.

Neste quadro, convém agora relembrar a trajetória do Programa Nacional de Alimentação Escolar. Como mencionam Belik e Chaim ${ }^{[1]}$, "O PNAE é o mais antigo programa social do Governo Federal na área de educação e é o maior programa de alimentação em atividade no Brasil". Seu embrião é concebido em 1950, no governo de Eurico Gaspar Dutra, com o Plano Nacional de Alimentação e Nutrição ${ }^{[2]}$.

A Campanha de Merenda Escolar (CME), homologada com o decreto $\mathrm{n}^{\circ} 37.106$, de 31 de março de 1955, faz parte de sua história. Trata-se do abastecimento alimentar de algumas escolas, em particular do Nordeste, graças, principalmente, a organismos internacionais. Mais tarde, a partir de 1979, a Campanha Nacional de Alimentação Escolar (antiga Merenda Escolar) passa a ser designada "Programa Nacional de Alimentação Escolar" (PNAE), denominação que vigora até hoje. Desde então, o PNAE deve cobrir todo o território nacional com caráter universal ${ }^{[2]}$.

Em sua evolução, convém destacar para nossos propósitos que, em 1994, o programa adotou, com a Lei $\mathrm{n}^{\mathrm{o}}$ 8.913, uma forma descentralizada de gestão, com vistas a promover seu controle por parte da sociedade civil e sistemas locais de abastecimento. Em 1998, a gestão descentralizada do PNAE, sob responsabilidade do Fundo Nacional de Desenvolvimento da Educação (FNDE), autarquia federal criada em 1968, é reforçada graças à transferência automática de seus recursos a estados e municípios pela medida provisória $\mathrm{n}^{\circ} 1.784^{[2]}$. Em 2000, a reedição desta última institui que cada município deveria contar com um conselho de alimentação escolar (CAE), órgão deliberativo, fiscalizador e de assessoria para a execução do PNAE. Em 2001, a medida provisória $\mathrm{n}^{\mathrm{o}} 2.178$ prescreve para a alimentação escolar o respeito aos hábitos alimentares locais e à vocação agrícola do 
município, favorecendo assim o desenvolvimento da economia local.

A Lei no 11.947 de 2009 prevê que a educação básica pública (ensino infantil, fundamental e médio, incluindo jovens e adultos, indígenas, quilombolas e aqueles matriculados no atendimento educacional especializado) deve contribuir para o desenvolvimento e a aprendizagem escolar dos estudantes, com a formação de hábitos alimentares saudáveis graças ao fornecimento de alimentação de qualidade e a ações de educação alimentar e nutricional. Assim, seu público alvo é considerado universalista, ao atender todas as etapas da educação básica.

Os objetivos do programa, desde seus primórdios, de acordo com Leonor Maria Pacheco dos Santos e seus colaboradores ${ }^{[3]}$, consistiram em suprir parcialmente as necessidades nutricionais de alunos de educação básica da rede pública e de escolas filantrópicas e comunitárias. De fato, os escolares são considerados como um grupo prioritário com vistas à segurança alimentar. A garantia do acesso a uma alimentação diária adequada permite diminuir a evasão e melhorar o desempenho escolar ${ }^{[2]}$.

Nesta perspectiva, a Lei n⿳ำ 11.947 de 2009, mencionada anteriormente, prescreve, pela primeira vez, disposições específicas com referência à agricultura familiar. A maior inovação desta lei está inscrita em seu artigo 14\%, determinando que, no mínimo, 30\% dos recursos transferidos pelo FNDE para complementar os orçamentos das entidades executoras $(\mathrm{EEx})^{6}$ para a alimentação escolar devem ser destinados à compra de produtos da agricultura familiar. Para este fim, são previstos procedimentos administrativos dispensando de licitação os alimentos provenientes da agricultura familiar. Em

\footnotetext{
${ }^{6}$ As entidades executoras podem ser prefeituras (para a gestão das escolas municipais), entes federativos (para a gestão das escolas estaduais) ou ainda escolas diretamente sob gestão federal.

${ }^{7}$ Segundo dados do extinto Ministério do Desenvolvimento Agrário (MDA, 2015), a agricultura familiar representa $84 \%$ de todos os estabelecimentos rurais no Brasil e mais de 5 milhões agricultores familiares possuem a Declaração de Aptidão ao Pronaf (DAP), o que lhes permite acesso a políticas
}

seu lugar, é autorizada a realização de chamadas públicas (sob a condição de que os preços sejam compatíveis com aqueles do mercado local), simplificando e agilizando estas aquisições públicas.

Além do apoio à agricultura familiar ${ }^{7}$, outra diretriz do programa é a preferência local para o abastecimento das escolas públicas. Trata-se do propósito de favorecer o desenvolvimento sustentável, graças ao incentivo para a aquisição de gêneros alimentares diversificados da agricultura familiar, produzidos em âmbito local, priorizando ainda as comunidades tradicionais indígenas e quilombolas. Ainda, assim como o Programa de Aquisição de Alimentos (PAA), há estimulo para a compra de produtos orgânicos ou agroecológicos na medida em que é possível majorar o preço pago ao produtor por estes produtos em até $30 \%$.

O descumprimento das normas em favor da agricultura familiar pode acarretar a suspensão da transferência de recursos do FNDE. Porém, justificações da EEx fundadas em eventual impossibilidade de adquirir alimentos de agricultores familiares podem ser aceitas.

Por outro lado, a lei recomenda a realização de investimentos na formação de recursos humanos envolvidos na execução do PNAE com vistas em particular a favorecer as compras dos produtos da agricultura familiar. Programas pedagógicos de educação alimentar são igualmente recomendados.

A Lei $n^{\circ} 11.947$ de 2009 foi posteriormente complementada por resoluções do conselho deliberativo do FNDE que detalham o funcionamento do PNAE. São consideradas neste artigo aquelas normas que se associam diretamente

\footnotetext{
públicas específicas. De acordo com o censo agropecuário de 2006 do Instituto Brasileiro de Geografia e Estatística (IBGE), os agricultores familiares são responsáveis pela maioria dos alimentos que chegam à mesa da população, como o leite (58\%), a mandioca ( $83 \%$ ) e o feijão $(70 \%)$. Assim, as políticas públicas voltadas à agricultura familiar desempenham importante papel para fomentar e valorizar o trabalhador rural.
} 
O lugar da agricultura familiar na alimentação escolar. Moruzzi Marques et al.

com a participação da agricultura familiar no programa.

A Resolução no 38 de 16 de julho de 2009 menciona, como a Lei n⿳0 11.947, que há dispensa do processo licitatório para a aquisição de produtos da agricultura familiar, não detalhando, porém, os procedimentos. Para a elaboração do cardápio pelo nutricionista técnico responsável, a resolução recomenda levar em conta a "diversificação agrícola da região", sem maiores precisões, e também a sazonalidade da produção familiar.

Recomenda igualmente priorizar, sempre que possível, a aquisição de alimentos orgânicos ou agroecológicos. Os preços para a aquisição dos gêneros alimentícios da agricultura familiar devem ser compatíveis com aqueles praticados no âmbito do Programa de Aquisição de Alimentos (PAA), de maneira que o limite individual de compras por agricultor familiar seja de $\mathrm{R} \$ 9.000,00 / \mathrm{DAP} /$ ano. A Resolução no 25 de 4 de julho de 2012 aumenta este limite individual para $\mathrm{R} \$$ 20.000,00/DAP/ano. Convém aqui explicar que DAP é a sigla do documento de aptidão ao Programa Nacional de Fortalecimento da Agricultura Familiar, que atesta a condição de agricultor familiar, segundo a definição da Lei $\mathrm{n}^{\mathrm{o}}$ 11.326/2006, que estabelece as diretrizes para a formulação da Política Nacional da Agricultura Familiar e Empreendimentos Familiares Rurais.

Já a Resolução no 26 de 17 de junho de 2013 esclarece procedimentos em torno da chamada pública, que deve se realizar para cumprir a exigência do artigo 14 da Lei no 11.947 referente à destinação de minimamente $30 \%$ dos recursos transferidos pelo FNDE para a compra de gêneros alimentares diretamente da agricultura familiar. À recomendação de priorizar sempre que possível os produtos orgânicos ou agroecológicos são acrescentados os produtos da sociobiodiversidade. A Entidade Executora pode acrescer até 30\% ao preço destes produtos em relação àqueles convencionais. Caso a Entidade Executora não consiga atingir a porcentagem exigida por lei através de fornecedores locais, poderá complementar o suprimento de alimentos com propostas de produtores familiares do território rural, do estado e do país, respectivamente.

Convém agora destacar que as nutricionistas desempenham um papel chave no PNAE, em termos de "planejar um cardápio nutritivo, com produtos de qualidade para a alimentação escolar. Com a compra da agricultura familiar, tem condições de adquirir produtos frescos, saudáveis, respeitando a cultura e a vocação agrícola local" "[2]. Suas atribuições no Programa Nacional de Alimentação Escolar são elencadas pela Resolução $n^{\circ} \quad 465 / 2010$ do Conselho Federal de Nutricionistas (CFN). Tratase de "realizar o diagnóstico e o acompanhamento do estado nutricional dos escolares; planejar, elaborar, acompanhar e avaliar os cardápios da alimentação escolar (...), respeitando a cultura alimentar e a vocação agrícola da região, utilizando produtos da agricultura familiar, sempre que possível, orgânicos e/ou agroecológicos (...)”.

É oportuno mencionar que, desde 2009, as compras da agricultura familiar no âmbito do PNAE crescem. Em 2015, o programa contou com R \$ 3,8 bilhões para aquisição de gêneros alimentícios. Considerando 30\% deste valor, $\mathrm{R} \$$ 1,14 bilhão deveriam ser destinados às aquisições de alimentos provenientes da agricultura familiar.

Portanto, o PNAE amplia o leque de instrumentos de apoio à agricultura familiar, concebidos desde meados de 1990 como fruto da crítica contra uma modernização agrícola que favoreceu grandes propriedades em estrutura agrária já muito concentrada e marginalizou as formas familiares de produção. Como sugere o estudo de Maria Elena Turpin ${ }^{[4]}$ examinando casos exitosos de gestão local eficiente de dispositivos vinculados ao PNAE, sua mobilização tem vocação de promover o desenvolvimento local. Assim, a autora menciona que, além da aquisição de alimentos da agricultura familiar (com melhora 
O lugar da agricultura familiar na alimentação escolar. Moruzzi Marques et al.

da qualidade da alimentação escolar), administrações municipais inovadoras atuaram em diferentes outras frentes. Entre as ações destacadas, cumpre citar o apoio na gestão dos estabelecimentos familiares para o fornecimento de alimentos às escolas, em particular no que se refere à agroindústria familiar, o suporte para a implantação ou o reforço de associações ou cooperativas de produtores familiares e o resgate da história do desenvolvimento local, focalizando o papel da agricultura familiar, visando inclusive sua "curricularização" no âmbito das disciplinas de ensino fundamental.

Enfim, nosso estudo tomou particularmente em conta os conselhos de alimentação escolar (CAE) dos municípios considerados, compostos, tal como determina a Lei $\mathrm{n}^{\mathrm{o}}$ 11.947, por representantes do poder executivo municipal, dos trabalhadores da educação, dos discentes, dos pais de alunos e de organizações da sociedade civil. Com efeito, os CAE são concebidos para assessorar a Entidade Executora, o FNDE e demais órgãos responsáveis pela execução do programa em termos de fiscalização da destinação dos recursos conforme as normas estabelecidas e de planejamento das ações do município no que se refere ao PNAE. Cálculos estimativos indicam que existem aproximadamente 80.000 conselheiros nos 5.570 municípios do Brasil, nos 26 estados e no Distrito Federal $^{[2]}$.

\section{REFERÊNCIAS TEÓRICAS E PROCEDIMENTOS METODOLÓGICOS}

A abordagem cognitiva das políticas públicas com seu conceito de referencial oferece instigantes elementos para a reflexão sobre as mudanças recentes no Programa Nacional de Alimentação Escolar. Para Pierre Muller ${ }^{[5]}$, uma política pública reflete de maneira mais ou menos clara as questões em torno da agenda sociopolítica em dado momento. Assim, as políticas públicas agroalimentares são definidas a partir das representações dos problemas agrícolas e alimentares, implicando em ajustes cognitivos com vistas a estabelecer os objetivos da ação pública e seus instrumentos. Estes últimos exprimem a visão, em determinado momento e em concorrência com outras concepções, de um referencial de como devem ser resolvidos os problemas agroalimentares.

Nesta linha de raciocínio, a ideia de fomentar a agricultura familiar local graças ao abastecimento em alimentos das escolas da rede pública se funda em referencial emergente de desenvolvimento sustentável da agricultura. Enfrentando muitas resistências apoiadas no referencial de regulação mercantil da agricultura, trata-se de uma mudança de quadros cognitivos e normativos associada à perspectiva do desenvolvimento sustentável e da agricultura multifuncional $\mathrm{l}^{[6,7,8]}$.

Neste âmbito, o referencial concebido por Catherine Darrot e Guy Durrant ${ }^{[9]}$ de circuitos curtos de proximidade (CCP) corresponde a uma versão bastante ampla do referencial de sustentabilidade no domínio agroalimentar. É claro que a emergência de tal referencial, afastando-se bastante dos princípios mercantis, suscita muita tensão em relação ao referencial de mercado.

Em outra ocasião, este referencial de CCP foi mobilizado para a análise do Programa de Aquisição de Alimentos ${ }^{[10]}$. Trata-se de referências fundadas em quatro pilares: social (equidade no acesso à alimentação de qualidade e solidariedade alimentar); ambiental (preservação da biodiversidade, da qualidade da água e do solo); econômico (preços justos, maior autonomia dos agricultores, maior valor agregado de seu produtos e transparência nas transações) e; alimentar (alimentos sem contaminantes, com grande qualidade organoléptica associada aos produtos do território). Efetivamente, estas fundamentações para a orientação da ação pública são muito úteis para considerar a concepção do PNAE e para analisar sua execução em escala local. 
O lugar da agricultura familiar na alimentação escolar. Moruzzi Marques et al.

Quanto aos procedimentos metodológicos, convém inicialmente mencionar que os elementos de análise foram obtidos, sobretudo, graças a entrevistas com atores chave nos três municípios escolhidos para a pesquisa (Americana, Cosmópolis e Piracicaba). As entrevistas, realizadas em 2015 e 2016, foram orientadas por roteiros específicos para membros do CAE, para nutricionistas técnico-responsáveis do programa, para outros profissionais implicados e para agricultores. A análise também contou com revisão da literatura e de documentos em torno do Programa Nacional de Alimentação Escolar.
No que se refere às composições dos CAE dos municípios considerados, aquele de Americana contava em 2015 com 15 membros. Foram entrevistados o presidente do conselho e a representante de pais de alunos. No município de Piracicaba, o conselho era composto por 11 membros e as entrevistas foram realizadas com sua presidente, uma representante dos profissionais da educação e uma representante de pais de alunos. No município de Cosmópolis, o conselho estava praticamente desativado, mas foi possível assim mesmo realizar uma entrevista coletiva com seus membros e outra com a nutricionista responsável técnica pelo programa no município. Os dados da tabela 1 oferecem um panorama da rede escolar dos três municípios.

Tabela 1. População estudantil das escolas estaduais e municipais dos municípios considerados na pesquisa

\begin{tabular}{c|c|c|c|c|c|c}
\hline \multirow{2}{*}{ Cidade } & \multicolumn{2}{|c|}{ Escolas Estaduais } & \multicolumn{2}{c|}{ Escolas Municipais } & \multirow{2}{*}{$\begin{array}{c}\text { Total } \\
\text { Total escolas }\end{array}$} & matrículas \\
\cline { 2 - 4 } & Unidades & Estudantes & Unidades & Estudantes & 101 & 29.467 \\
Americana & 57 & 18.791 & 44 & 10.676 & 31 & 10.396 \\
Cosmópolis & 08 & 2.977 & 23 & 7.419 & 231 & 55.375 \\
Piracicaba & 103 & 31.556 & 128 & 23.819 & 231 & 19 \\
\hline
\end{tabular}

Fonte: Instituto Brasileiro de Geografia e Estatística IBGE, 2016 [11]. Obs.: em todos os municípios não há ensino pré-escolar oferecido por escolas estaduais.

\section{DISCURSOS SOBRE A ALIMENTAÇÃO ESCOLAR E O FUNCIONAMENTO LOCAL DO PNAE}

Nesta parte do artigo, focalizaremos as visões e as ações dos conselheiros da alimentação escolar, das nutricionistas e demais envolvidos com o programa nos municípios considerados na pesquisa em torno dos Conselhos da Alimentação Escolar. Neste ponto, convém salientar que uma ação intersetorial é frequentemente apresentada como desejável para a execução do Programa Nacional de Alimentação Escolar. Portanto, é requerida uma organização político-administrativa que favoreça a interação entre profissionais da educação, saúde e agricultura, inclusive com vistas ao fomento do desenvolvimento local.
As dinâmicas em torno desta ação intersetorial ocorrem de forma bastante distinta nos municípios estudados. Quando da realização da pesquisa de campo, as gestões dos CAE considerados se encontravam em seu primeiro ano de mandato, previsto para quatro anos. Muitos entrevistados mencionaram que não seria necessário apenas o "desenvolvimento de fornecedores" para o bom funcionamento do PNAE, mas também o "desenvolvimento de executores", termos empregados por Walter Belik e Luciana Souza ${ }^{[12]}$. Ou seja, o corpo administrativo municipal responsável pelas compras e fiscalização no âmbito do programa deveria ser capacitado. A propósito, como sugere Retière ${ }^{[13]}$, a reduzida participação dos agricultores familiares no fornecimento da alimentação escolar é em boa 
medida decorrente do desconhecimento da realidade agrícola local pelos responsáveis da elaboração das chamadas públicas.

Para a apresentação dos resultados obtidos em nossa pesquisa, foram concebidas três categorias para os CAE estudados: 1 - favorável à inovação (Piracicaba); 2 - em reestruturação avançada (Americana) e; 3 - em fase inicial de reestruturação (Cosmópolis).

No caso do conselho favorável à inovação, uma interlocutora explicou que, nas reuniões realizadas pelo CAE, são convidadas as nutricionistas responsáveis técnicas, os profissionais da empresa terceirizada para alimentação de escolas estaduais e membros da delegacia de ensino. Ainda complementa que, por serem reuniões mensais, a maioria tem condição de participar: "as atas são enviadas para todos por email e grande parte da comunicação se dá através deste [meio de comunicação eletrônico], visto que o contato de todos é de fácil acesso". Estas reuniões ocorrem cada mês em local diferente, mas sempre em dependências de um órgão com incumbência no PNAE (por exemplo, na Secretaria Municipal de Educação ou no setor de compras do município). Como afirma a entrevistada, "eles nos convidam para muitas atividades também, onde a prefeitura dá apoio ao CAE, articulando os gastos e requisitos necessários para que participemos". Assim, a prefeitura favorece o deslocamento dos conselheiros para visitas a escolas para fiscalizar quesitos com ressalvas, segundo as normas do FNDE. Para tanto, uma estreita articulação do CAE com a delegacia de ensino assegura o acompanhamento das visitas.

Ainda em Piracicaba, uma conselheira entrevistada assegura que os $30 \%$ das compras de alimentos destinados às escolas provenientes da

\footnotetext{
8 Ver este site para consultas do FNDE http://www.fnde.gov.br/programas/alimentacao-escolar/alimentacaoescolar-consultas/dados-da-agricultura-familiar.

9 Os principais alimentos adquiridos da agricultura familiar por esta administração eram: suco de laranja e iogurte, provenientes de Engenheiro
}

agricultura familiar são alcançados. Contudo, a nutricionista responsável técnica atuante no programa considera que existem "dificuldades de logística de entrega e baixa oferta de produtos da agricultura familiar em determinadas épocas”. Os preços também não são sempre satisfatórios. Apesar das dificuldades, "os agricultores vêm se organizando melhor e recebendo maior apoio".

Assim, neste município, são realizados esforços da administração municipal para que os agricultores possam conhecer melhor o programa a fim que participem das chamadas públicas. É a Secretaria Municipal de Agricultura em parceria com o Departamento de Alimentação e Nutrição quem realiza este tipo de fomento junto aos agricultores. No entanto, segundo um de nossos interlocutores, "ainda há um longo caminho a ser percorrido". Logo, o fomento ao desenvolvimento local graças ao programa é muito reduzido. Neste município, foram destinados, em 2015, 40,18\% dos valores transferidos pelo FNDE para aquisição de produtos da agricultura familiar visando o fornecimento da alimentação escolar. ${ }^{8}$ Porém, estes alimentos não são provenientes, em boa parte, de estabelecimentos situados em Piracicaba ${ }^{9}$. De todo modo, os gestores públicos deste município manifestam a importância de promover um desenvolvimento local sustentável.

Por outro lado, os agricultores entrevistados demonstram pouco conhecimento sobre políticas públicas de comercialização para produtos da agricultura familiar, tendo informações superficiais sobre o PNAE, obtidas graças a diálogos especialmente com colegas de feiras/varejões. Portanto, as ações visando a divulgação do programa parecem pouco eficazes, com dificuldades para atingir o agricultor familiar.

Convém mencionar aqui que um agricultor entrevistado, ocupando a presidência de

Coelho e São Pedro, distantes cerca de $70 \mathrm{~km}$ e $45 \mathrm{~km}$ de Piracicaba, respectivamente; leite em pó e arroz orgânico, vindos do Rio Grande do Sul, e; frutas e hortaliças, produzidas no município de Piracicaba. 
O lugar da agricultura familiar na alimentação escolar. Moruzzi Marques et al.

uma cooperativa local, manifestou notável interesse em participar dos conselhos municipais, em particular do CAE. De fato, esta cooperativa é sempre representada nas reuniões mensais do Conselho Municipal de Segurança Alimentar e Nutricional (COMSEA), o que corresponde às prescrições veiculadas pelo extinto Ministério Extraordinário de Segurança Alimentar e Combate à Fome (MESA), em 2003, para que se multipliquem debates mais plurais com vistas ao alcance do objetivo público de consolidar uma rede municipal de educação capaz de fornecer refeições saudáveis fomentando a economia local baseada em princípios sustentáveis. Apesar de uma incipiente relação do CAE com profissionais da área de abastecimento alimentar do município, membros deste conselho pensam em, futuramente, trabalhar em conjunto para atingir objetivos comuns, em particular aquele de fomentar a economia local ${ }^{10}$.

$\mathrm{Na}$ perspectiva de uma das entrevistadas, "o impacto do programa para o agricultor familiar, no sentido de desenvolver a região, é importantíssimo, pois o dinheiro fica aqui, você não precisa transportar [o alimento] de longe. Você desenvolve o pequeno agricultor e incrementa a economia local, isso está comprovado que acontece". Embora este tipo de manifestação permita considerar um importante engajamento em favor da agricultura familiar resultando em iniciativas promissoras, as repercussões do PNAE em termos de desenvolvimento local são muito modestas, como já mencionado.

No município cujo CAE está em situação de reestruturação avançada, a interação entre os atores esteve bloqueada em razão, sobretudo, de problemas políticos-administrativos em torno da última gestão do conselho. Como examinou Morgane Retière ${ }^{[13]}$, este município sofreu com repetidos escândalos envolvendo autoridades locais. Em 2014, ocorreu a destituição do prefeito e a realização de novas eleições municipais. Estes infortúnios entravam as atividades do CAE, pois os conselheiros devem se ocupar da montagem de um quebra-cabeça para responder aos questionamentos das instâncias superiores responsáveis pelo PNAE, que constataram irregularidades nos relatórios enviados ao FNDE.

Quando da realização da pesquisa, os conselheiros estavam, portanto, regularizando a prestação de contas do CAE em colaboração com o poder executivo municipal. Assim, as reuniões do conselho passaram a ocorrer quando foram tomadas iniciativas visando a regularização da gestão da alimentação escolar. Desta forma, a articulação entre diferentes atores envolvidos com o programa era muito reduzida. A inexistência de uma secretaria de agricultura em Americana não contribui para uma ação intersetorial, tratando-se em grande medida de uma negligência com a atividade agrícola local.

Neste quadro, de acordo com nossos interlocutores, o CAE e a nutricionista responsável pela alimentação escolar estão distantes. Convém insistir sobre o papel esperado destes profissionais no programa: "compete ao nutricionista responsável-técnico, no âmbito de suas atividades obrigatórias, interagir e orientar o CAE no que diz respeito à execução técnica do PNAE"[14].

Com efeito, esta gestão do CAE sofreu os efeitos de uma administração pública municipal deplorável, o que impediu a observação das orientações do Ministério da Educação. Em seus documentos, este último recomenda que, ao término do mandato, os novos conselheiros tenham acesso às atividades que estavam em andamento, sendo necessário, portanto, que o conselho tenha arquivado os documentos relativos às atividades desenvolvidas. Também é recomendável a instituição de uma comissão que auxilie no repasse de informações para a nova gestão $^{[2]}$.

${ }^{10}$ A propósito, uma de nossas interlocutoras avalia positivamente a intenção da secretaria local de abastecimento de realizar o mapeamento dos agricultores locais. 
O principal motivo que um dos conselheiros de Americana alegou, quando questionado sobre iniciativas visando o aumento da participação da agricultura familiar no fornecimento da alimentação escolar no município, foi que não havia tempo hábil para se dedicar a este trabalho. Os conselheiros investiram grande parte de seu tempo em organizar informações e cumprir exigências burocráticas, em particular a prestação de contas da anterior e atual gestão.

Por outro lado, um de nossos interlocutores revela que os agricultores do município não compareciam às chamadas públicas pois a prefeitura tenderia a atrasar os pagamentos. Com todos estes problemas, este município não cumpre o artigo 14 de Lei no 11.947. Segundo os dados do FNDE, Americana destina apenas $17,08 \%$ dos valores repassados por esta fundação para a aquisição de gêneros alimentares oriundos da agricultura familiar. Em 2016, estas compras aumentaram, segundo a nutricionista responsável, graças a alimentos como suco de laranja, suco de uva integral e iogurte, provenientes respectivamente de São José do Rio Preto e de cooperativas do Rio Grande do Sul e de Brodowski. Além destes produtos, hortaliças orgânicas são compradas de uma estrutura local, a Cooperativa da Agricultura Familiar e Agroecológica (Cooperacra).

De toda forma, grande parte dos esforços dos conselheiros deste município se concentrava, quando da realização das entrevistas, na resolução de problemas herdados da administração municipal anterior. Então, havia um imenso esforço dos membros do CAE para cumprir as exigências burocráticas do PNAE, com vistas a retomar adequadamente um dispositivo com muitas potencialidades. De fato, os conselheiros do município de Americana estimam que o programa é "favorável por gerar renda local, por poder auxiliar na diminuição da criminalidade (por ser inclusivo), por proporcionar alimento de qualidade para crianças" e por cada "cidadão ajudar outro cidadão (agricultor), para fazer a cidade melhorar, para circular dinheiro".

No que se refere ao município com CAE em fase inicial de reestruturação, seus conselheiros desejam superar as dificuldades para ativar o conselho e atuar no sentido de permitir que até o fim de sua gestão possam, ao menos, conduzir a prefeitura a realizar as compras institucionais para a alimentação escolar com a porcentagem mínima de participação de produtos da agricultura familiar, tal como exigido pela Lei no 11.947 de 2009. De todo modo, neste município, houve, em anos anteriores, abastecimento de parte da alimentação escolar com produtos oriundos da agricultura familiar local, graças a apenas dois agricultores. Estes últimos eram tidos como fornecedores individuais, pois se tratava de agricultores não organizados, possuindo DAP física. No entanto, com a alegação de que não se tratava de grupos formais de agricultores familiares, este fornecimento local de alimentos para as escolas foi interrompido em favor de produtos não perecíveis da agricultura familiar da região Sul do país.

Em Cosmópolis, os membros do conselho possuíam poucas informações quanto ao funcionamento do PNAE, quanto à agricultura familiar do município e, sobretudo, quanto às incumbências do próprio CAE. Efetivamente, realizavam apenas visitas para conferência da qualidade dos produtos alimentares disponibilizados nas escolas.

Desta forma, as reuniões mensais nem sempre ocorriam. Esses limites e dificuldades se explicam em parte pela centralização das informações em poucos atores, como a nutricionista técnica responsável - que manifesta de todo modo seu interesse por acompanhar as atividades do CAE, mas alega pouca disponibilidade de tempo para tal - e o presidente do conselho, que se afastou da função por volta de março de 2016. 
Apesar de tudo, esforços para o cumprimento da lei são realizados, graças principalmente ao empenho da nutricionista técnica responsável que, em virtude de um curso realizado em São Paulo, teve contato com uma cooperativa de agricultores familiares do Sul do país que fornece macarrão, arroz, óleo e leite em pó para a alimentação escolar de Cosmópolis. Desta forma, a administração municipal chegou em 2015 a adquirir produtos da agricultura familiar na ordem de 19,18\% do que é transferido pelo FNDE, o que é, todavia, aquém das exigências legais.

Neste município se localiza parte do assentamento Milton Santos. Em 2013, dois agricultores assentados forneceram mandioca para as escolas públicas municipais graças às orientações do PNAE. Com a perspectiva de aumentar este fornecimento, os agricultores compraram uma máquina de embalar mandioca (descascada) a vácuo. Porém, este item não voltou a ser solicitado nas chamadas públicas da prefeitura. De acordo com a nutricionista técnica responsável, a falta de espaço nas escolas impede o armazenamento deste tipo de produto. São evidentes, portanto, as falhas de comunicação, o que leva agricultores a investimentos sem uma orientação adequada.

Este imbróglio tornou estas famílias assentadas avessas a participar do programa. Ademais, há frequentemente incompatibilidade dos produtos solicitados com os produtos disponíveis no assentamento, o que concorre com outras dificuldades (como ausência de transporte para distribuir os alimentos por parte das prefeituras ou grande burocracia para os pagamentos) para uma maior participação dos assentados nas chamadas públicas, tal como analisou Morgane Retière ${ }^{[13]}$.

\section{CONCLUSÃO}

Nossa pesquisa permitiu constatar que todas as prefeituras estudadas (Piracicaba,
Americana e Cosmópolis) realizam compras de produtos da agricultura familiar. Porém, o fomento ao desenvolvimento local, tal como preconizado pelas orientações do PNAE, é muito limitado. As compras de produtos da agricultura familiar estabelecida nos municípios considerados se restringem a folhosas.

Frequentemente, para tentar atingir o mínimo de 30\% da destinação dos recursos do FNDE para a aquisição de gêneros alimentícios advindos da agricultura familiar, as prefeituras recorrem a organizações distantes de agricultores familiares. Estas últimas fornecem então produtos tais como suco de laranja, feijão, leite, iogurte (produzidos na maior parte em outras regiões do estado de São Paulo) e suco de uva (proveniente da região Sul do país). No caso das aquisições de Cosmópolis, muitos produtos não perecíveis (macarrão, arroz, óleo e leite em pó) também são produzidos na região Sul do país. O fomento ao desenvolvimento local pouco se cumpre também em razão de uma alocação insuficiente de recursos repassados pelo FNDE para a aquisição de produtos da agricultura familiar. Em 2015, os dados do Fundo Nacional do Desenvolvimento da Educação revelam que Americana e Cosmópolis destinaram menos de $20 \%$ destes valores para tal fim, o que está aquém do que é exigido por lei.

Nesta linha de raciocínio, convém também salientar que o conhecimento do programa pelos membros dos CAE entrevistados é pouco consistente. Efetivamente, são as nutricionistas com responsabilidades sobre a elaboração dos cardápios das escolas que possuem mais informações sobre o PNAE, além de outros poucos membros dos conselhos.

Junto aos agricultores entrevistados, foi possível obter depoimentos sobre dificuldades em participar do programa. As deficiências de comunicação constituem o principal problema. Em Piracicaba, o apoio da secretaria da agricultura e do setor de compras alimentares levou à formação de uma cooperativa para fornecimento 
O lugar da agricultura familiar na alimentação escolar. Moruzzi Marques et al.

de folhosas para a alimentação escolar. Entretanto, esse tipo de ação não ocorre nos demais casos considerados. A inexistência de secretaria da agricultura em Americana tende a agravar o problema neste município.

Cumpre ressaltar que a afinidade com o tema da alimentação escolar ou da agricultura familiar favorece sobremaneira uma execução adequada do programa, considerando seus objetivos. O exemplo de Piracicaba, cuja presidência do conselho (exercida por acadêmica especializada em questões relativas à segurança alimentar e integrante também do Conselho Municipal de Segurança Alimentar e Nutricional) estimula um debate local sobre o programa, apresenta um quadro de difusão de informações mais favorável à criação de condições para que a agricultura familiar local participe do PNAE. A propósito, os conselheiros entrevistados manifestam uma reação positiva em relação a iniciativas que promovam esclarecimentos e fomentem discussões a respeito do programa, tais como seminários organizados pelos Centros Colaboradores em Alimentação e Nutrição do Escolar (CECANE).

Enfim, a pesquisa permitiu identificar um perfil multifacetado dos conselheiros do CAE. No entanto, há uma sub-representatividade dos agricultores familiares, cujo interesse pelo programa de alimentação escolar é em princípio evidente.

\section{REFERÊNCIAS}

[1] Belik W, Chaim NA. O programa Nacional de Alimentação Escolar e a gestão municipal: eficiência administrativa, controle social e desenvolvimento local. Rev Nutri. 2009;5(22):595-607.

[2] Fundo Nacional de Desenvolvimento da Educação FNDE. Cartilha Nacional da Alimentação Escolar [internet]. Brasilia; 2015 [acesso em 07 nov 2016]. Disponível em: http://www.fnde.gov.br

[3] Santos LMP, Santos SMC, Santana LAA, Henrique FCS, Mazza RPD, Santos LAS, et al. Avaliação de políticas públicas de segurança alimentar e combate à fome no período 19952002: Programa Nacional de Alimentação Escolar. Cad Saúde Pública. 2007:23(11):2681-2693.

[4] Turpin ME. A Alimentação Escolar como fator de desenvolvimento local por meio do apoio aos agricultores familiares. Segur Aliment Nutri. 2009;16(2):20-42.

[5] Muller P. Les politiques publiques. Paris: PUF; 2003.

[6] Carneiro MJ, Maluf R. Para além da produção: multifuncionalidade e agricultura familiar. Rio de Janeiro: Mauad; 2003.

[7] Rémy J. Um caminho sinuoso e semeado de espinhos os agricultores franceses: da especialização e intensificação da produção à multifuncionalidade e ao desenvolvimento sustentável. Estudos Sociedade e Agricultura. 2004;12(1):0550 .

[8] Cazella A, Bonnal P, Maluf RS. Agricultura familiar, multifuncionalidade e desenvolvimento territorial no Brasil. Rio de Janeiro: Mauad, 2009.

[9] Darrot C, Durant G. Référentiel central des circuits courts de proximité: mise en évidence et statut pour l'action. In : Traversac JB. Circuits courts: contribution au développement régional. Dijon: Educagri éditions; 2010.

[10] Moruzzi Marques PE, Moal ML, Andrade AGF. Programa de Aquisição de Alimentos (PAA) no estado de São Paulo: agricultura de proximidade em questão. Ruris. 2014;8:63-89.

[11] Instituto Brasileiro de Geografia e Estatística - IBGE. Cidades 2016 [internet]. Rio de Janeiro; 2016 [acesso em 16 jan 2016]. Disponível em: http://cidades.ibge.gov.br

[12] Belik W, Souza LR. Algumas reflexões sobre os programas de alimentação escolar na América Latina. Planejamento e Políticas Públicas. 2009;1(33):103-122.

[13] Retiere M. Agricultores inseridos em circuitos curtos de comercialização: modalidades de venda e adaptações dos sistemas agrícolas [dissertação]. Piracicaba: ESALQ-CENA da Universidade de São Paulo; 2014.

[14] Vasconcelos FAG, Corso ACT, Trindade EBCM, Zeni LAZR, Gazzola J, Kazapi IAM, Saraiva EB, Viteritte PL. O papel do nutricionista no Programa Nacional de Alimentação Escolar (PNAE). 2.ed. Brasilia: PNAE; 2012. 